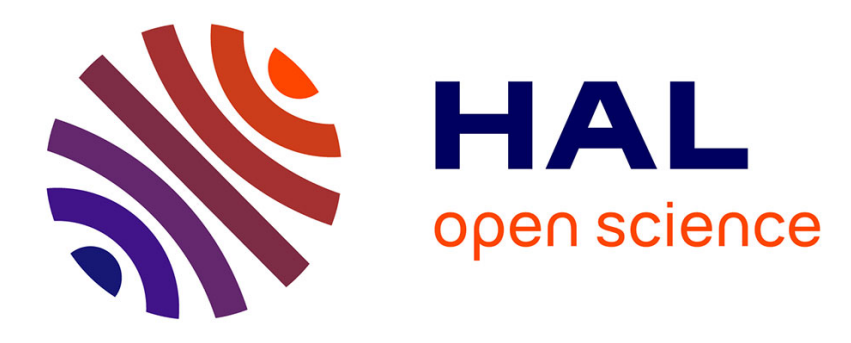

\title{
Thermal Effects versus Viscoelasticity in Ice-Rubber Friction Mechanisms
}

\author{
S Hemette, Juliette Cayer-Barrioz, D Mazuyer
}

\section{To cite this version:}

S Hemette, Juliette Cayer-Barrioz, D Mazuyer. Thermal Effects versus Viscoelasticity in Ice-Rubber

Friction Mechanisms. Tribology International, 2021, 10.1016/j.triboint.2021.107129 . hal-03357899

\section{HAL Id: hal-03357899 \\ https://hal.science/hal-03357899}

Submitted on 29 Sep 2021

HAL is a multi-disciplinary open access archive for the deposit and dissemination of scientific research documents, whether they are published or not. The documents may come from teaching and research institutions in France or abroad, or from public or private research centers.
L'archive ouverte pluridisciplinaire $\mathbf{H A L}$, est destinée au dépôt et à la diffusion de documents scientifiques de niveau recherche, publiés ou non, émanant des établissements d'enseignement et de recherche français ou étrangers, des laboratoires publics ou privés. 


\section{Journal Pre-proof}

Thermal Effects versus Viscoelasticity in IceRubber Friction Mechanisms

S. Hemette, J. Cayer-Barrioz, D. Mazuyer

PII: $\quad$ S0301-679X(21)00277-2

DOI: $\quad$ https://doi.org/10.1016/j.triboint.2021.107129

Reference: JTRI107129

To appear in: Tribiology International

Received date: 4 February 2021

Revised date: 3 June 2021

Accepted date: 8 June 2021

Please cite this article as: S. Hemette, J. Cayer-Barrioz and D. Mazuyer, Thermal Effects versus Viscoelasticity in Ice-Rubber Friction Mechanisms, Tribiology International, (2021) doi:https://doi.org/10.1016/j.triboint.2021.107129

This is a PDF file of an article that has undergone enhancements after acceptance, such as the addition of a cover page and metadata, and formatting for readability, but it is not yet the definitive version of record. This version will undergo additional copyediting, typesetting and review before it is published in its final form, but we are providing this version to give early visibility of the article. Please note that, during the production process, errors may be discovered which could affect the content, and all legal disclaimers that apply to the journal pertain.

(C) 2021 Published by Elsevier. 


\title{
Thermal Effects versus Viscoelasticity in Ice-Rubber Friction Mechanisms
}

\author{
S. Hemette ${ }^{\mathrm{a}}$, J. Cayer-Barrioz ${ }^{\mathrm{a}, 1}$, D. Mazuyer ${ }^{\mathrm{a}}$ \\ ${ }^{a}$ Laboratoire de Tribologie et Dynamique des Systèmes, CNRS UMR5513, Ecole Centrale de Lyon, 36 \\ avenue Guy de Collongue, 69130 Écully, France
}

\begin{abstract}
This work presents an experimental analysis of the friction response of an ice-rubber interface over five decades of sliding velocity and temperature down to $-20^{\circ} \mathrm{C}$, combining in-situ contact visualisation and simultaneous force measurements. Viscoelastic properties of the rubber were varied in terms of glassy temperature transition and elastic modulus. Based on the in-situ contact area measurements, the adhesive and viscoelastic contributions were identified. Even though a bell-shape friction-velocity curve was observed, the classical WLF transform did not allow a description of the friction behaviour. A simple analytical model accounting for the thermal dissipation induced by friction was thus proposed and a dimensionless master curve was obtained with the sliding velocity, regardless of the temperature and the material properties. From this master curve, a predictive friction model was proposed, in which both friction contributions, adhesion-viscoelasticity and thermal dissipation, were multiplicative rather than simply additive.
\end{abstract}

Keywords: Adhesion, Cold environment, Elastomer, JKR, Modelling, Sliding friction.

\section{Introduction}

From road safety when driving on icy roads to public health when walking on icy pavement with rubber sole shoes, ice-rubber contacts occur everywhere and are part of our every day life. However, the nature of the contact itself and the mechanisms of frictional dissipation

\footnotetext{
${ }^{1}$ Corresponding author. Laboratoire de Tribologie et Dynamique des Systèmes, CNRS UMR5513, Ecole Centrale de Lyon

Address: 36 avenue Guy de Collongue, 69134 Ecully, France.

Tel.: +33 4 72186284; fax: +33478433383 .

E-mail address: juliette.cayer-barrioz@ec-lyon.fr (J. Cayer-Barrioz).
} 
remain largely unknown. This has led to increasing interest in the tribology community, to unveil ice-rubber friction mechanisms.

On the one hand, ice is very complex. It is usually a polycrystalline material whose crystals are randomly oriented due to temperature, pressure conditions or nucleation seeds. Ice solid phases exist in different forms. However, under the pressure and temperature conditions present on Earth, typically up to $30 \mathrm{MPa}$ and above $200 \mathrm{~K}$, the hexagonal Ih phase is stable [1]. The slipperiness of ice is often attributed to the existence of a 'quasi-liquid' layer below the melting point of ice. Even though still under debate, the mechanisms that extend the equilibrium domain of a liquid phase into a solid domain range from incomplete integration of $\mathrm{H}_{2} \mathrm{O}$ molecules at the surface into the ice crystalline structure, to thermodynamic considerations of the ice-air interface and the persistence of a melted layer over a finite temperature range [2].

On the other hand, rubber is a composite material made of a crosslinked elastomer matrix with various additives, such as fillers (silica and carbon black particles) to improve its mechanical properties, plasticizers to facilitate its mixing during processing, and vulcanization agents. This structural complexity results in non-linear viscoelasticity and adhesion. Rubber tribology was thus extensively investigated during the 20th century in response to the massive development and use of elastomeric products. Once in a sliding contact, rubbers behave very differently from metals. In dry contacts, rubber friction results from three main contributions [3]: hysteresis, adhesion and wear. The hysteresis friction can be related to local rubber deformation due to the counter-surface and to viscoelastic bulk deformation. The number of asperities in contact, their geometry as well as the viscoelasticity of the rubber itself drive the hysteresis friction within certain limits. Grosch amongst others, investigated rubber hysteretic friction against smooth and rough surfaces [4]. A bell-shape friction curve was observed as a function of the sliding velocity exhibiting more or less asymmetry and primary and secondary peaks depending on the degree of roughness. A friction master-curve was built thanks to the William-Landel-Ferry (WLF) transform, demonstrating the major role of rubber viscoelasticity in the friction response. The primary friction peak was quantitatively related to the maximum in dissipative modulus due to the passage of the asperities, while the secondary peak was attributed to the interfacial bonding, that is to say, adhe- 
sion loss [5]. This dissipative process involved the attachment, straining and detachment of rubber segments [5]. Several adhesive theories were reviewed in [5]. They all included a viscoelastic loss factor and they were proposed to explain this adhesion contribution, either at the macroscopic [6] or molecular scale [7] [8] [9]. Savkoor's model [6] was based on the formation and breaking of bonding domains between the rubber and the counter-surface. An energy criterion was considered as being the breaking of the bonds that occurred when the elastic energy stored in the sheared bond equalled the adhesion energy-originating from van der Waals forces [6]. At the molecular scale, the central idea was that surface atoms of both surfaces interacted locally during sliding. These bonds were formed, strained and then broken according to a thermally activated process [7] [8] [9] and their kinetics depended on several characteristic times-dependent on the dynamics and lifetime of the bonds [8].

Friction on ice strongly depends on the composition of the sliding partner: sliding against granite resulted in a bell-shape friction curve while sliding on steel led to the lowest friction value, independent of the sliding velocity, despite the two materials having similar roughness [10]. This discrepancy of behaviour was attributed to a combination of adhesion, ice creep and frictional heating or melting [10] [11] [12]. Against rubber, the mechanisms are even more complex since there is an interplay between temperature, sliding velocity, contact pressure, surface roughness and variability in the ice. Various authors [13] [14] [15] have investigated the friction response of ice-rubber as a function of velocity and temperature: they obtained a bellshape curve and were able to build a master curve from a WLF transform. Nevertheless, an increase in temperature always resulted in a drop in friction: close to the melting temperature, the change in behaviour was interpreted as being the formation of a 'quasi-liquid' layer or a melt ice layer [13] [14] [15] [16] [17].

To sum up, the temperature strongly affects the friction response by modifying the ice surface enhancing adhesion and promoting the presence of a 'quasi-liquid' or melted viscous layer and by inducing a variation in rubber viscoelasticity. The sliding velocity can be related to the temperature increase in the contact but can also influence the frequency of stress imposed on the rubber surface and thus its viscoelastic deformation. The commonly accepted view is that viscoelasticity dominates at low sliding velocity, while thermal effects govern the dissipation at high velocity. Figure 1 summarizes the mechanisms responsible for 


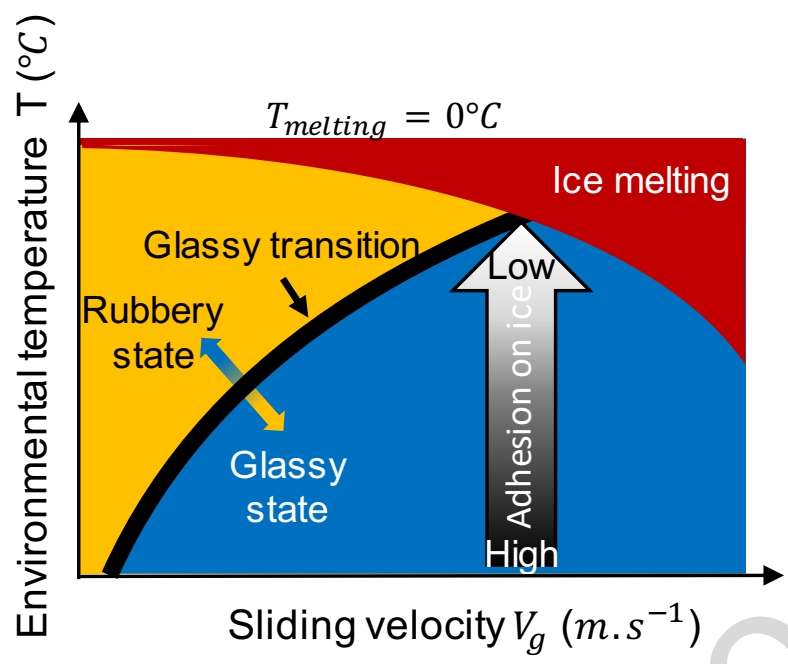

Figure 1: Schematic mapping of the expected friction mechanisms as a function of the temperature and the sliding velocity. From [12]

friction dissipation between ice and rubber, identified from the literature.

Against this background, the goal of this paper is to address the challenge of the origin of frictional dissipation at an ice-rubber sliding interface, and to elucidate the relative contributions of thermal and viscoelasticity-adhesion effects.

\section{Materials and Methods}

An ice disc, $90 \mathrm{~mm}$ in diameter and $500 \mu \mathrm{m}$ thick, was prepared from distilled water according to the protocol described in [18]. Deposited on a $90 \mathrm{~mm}$ diameter silica disc, it had the advantages of being homogeneous and transparent, while exhibiting a flat surface after tooling.

The three tested elastomer materials were composed of a styrene-butadiene matrix vulcanized with commercial-grade sulfur-donor and accelerators. Plasticizers, as well as silica and carbon fillers, were added. The viscoelastic properties were varied by changing the concentrations of the plasticizers. The detailed description of the composition, including providers, chemical nature of each component and concentrations, can be found in [19]. The bulk mechanical properties were analyzed by means of Dynamic Mechanical Analysis (DMA) (Metravib VA4000 at Nihon Michelin) at different frequencies, for deformation strains of $0.2 \%$ and $10 \%$ from -80 to $+80^{\circ} \mathrm{C}$ at a rate of $2^{\circ} \mathrm{C} / \mathrm{min}$. In this paper, three rubbers, representative 
Table 1: Mechanical properties and surface morphologies of the investigated rubbers. The shear modulus plateau $G *$ and glass temperature $T_{g}$ were measured by Dynamic Mechanical Analysis (DMA) for a frequency of $30 \mathrm{~Hz}$ and a deformation strain of $10 \%$.

\section{$\begin{array}{llll}\text { Sample } & \text { Rubber } 1 & \text { Rubber } 2 & \text { Rubber } 3\end{array}$}

\begin{tabular}{cccc}
\hline Shear modulus $G *(M P a)$ & 1.0 & 1.0 & 1.4 \\
Glass Temperature $T_{g}\left({ }^{\circ} \mathrm{C}\right)$ & -50 & -40 & -50 \\
Agglomerate mean diameter $(\mu \mathrm{m})$ & $26.3 \pm 10.8$ & $33.5 \pm 16.4$ & $27.0 \pm 16.9$ \\
Agglomerate mean height $(\mu \mathrm{m})$ & $2.85 \pm 1.25$ & $3.0 \pm 1.6$ & $3.2 \pm 1.5$ \\
Surface density (agglomerates $\left./ \mathrm{mm}^{2}\right)$ & 38.9 & 38.9 & 44.5 \\
\hline
\end{tabular}

of real tires, were investigated. Their properties are indicated in table 1. The rubber surface was analysed by means of optical microscopy. The rubber surfaces contained heterogeneities, corresponding to agglomerates of filler aggregates. The surface density and the diameter of these agglomerates were estimated at $40 / \mathrm{mm}^{2}$ and $30 \mu \mathrm{m}$ respectively, regardless of the rubber viscoelastic properties. These surface morphological parameters are also reported in table 1. However, the visualization of a static contact between these rubbers and a smooth glass disc under $10 \mathrm{~N}$ seemed to indicate that the surfaces could be considered as smooth.

Johnson-Kendall-Roberts (JKR) and friction experiments were performed using the KŌRI tribometer. The contact was realized between an ice disc and a rubber barrel under controlled contact kinematics in a cold, dry environment, with simultaneous in-situ contact visualization and measurements of contact, normal and frictional forces. The technical details of the KŌRI tribometer are presented in detail in [18]. The fixed rubber barrel was formed by compressing an initial rubber cylinder between two steel plates: the two radii of curvatures (in both directions) were measured at $R_{a}=32.5 \mathrm{~mm}$ and $R_{b}=15.5 \mathrm{~mm}$ for a barrel length of 11.9 $m m$.

Once the ice had been machined to ensure disc flatness (see [18]) and was in thermal equilibrium with the environment, JKR and friction experiments were carried out for each rubber.

During JKR experiments, the normal force was applied stepwise, up to $10 \mathrm{~N}$ with a resolution better than $0.1 \mathrm{~N}$. The cold (dry) air temperature of the environment was either 
Table 2: Summary of the experimental conditions, with the normal force $F_{z}$, the environmental temperature $T_{0}$ and the sliding velocity $V$

\begin{tabular}{cccc}
\hline Experiment & $F_{z}(N)$ & $T_{0}\left({ }^{\circ} \mathrm{C}\right)$ & $V(\mathrm{~m} / \mathrm{s})$ \\
\hline JKR experiment & 0 to 10 & -2.5 and -10 & 0 \\
Friction experiment & 10 & -20 to -2.5 & $50.10^{-6}$ to 1 \\
\hline
\end{tabular}

$-10^{\circ} \mathrm{C}$ or $-2.5^{\circ} \mathrm{C}$. The apparent static contact area was measured for each loading/unloading step at two different positions on the ice.

During friction experiments, the applied normal force was set at $10 \mathrm{~N}$. The ice disc rotational velocity, $V$, was ranging from $50 \mu \mathrm{m} / \mathrm{s}$ to $1 \mathrm{~m} / \mathrm{s}$. A logarithmic velocity-ramp of 14 steps of $30 \mathrm{~s}$ each was used. The resulting sliding distance varied between $1.5 \mathrm{~mm}$ and 30 $m$. Each measurement was repeated three times. The air temperature of the environment ranged between -20 and $-2.5^{\circ} \mathrm{C} .100$ images of apparent dynamic contact area were acquired during each velocity step and post-processed using the 'Phantom imaging' algorithm, fully described in [18].

These experimental conditions, reported in table 2, were chosen in order to be representative of real tire working conditions, in terms of contact pressure, temperature and sliding velocities.

\section{Results and Discussion}

\subsection{Contact mechanics and adhesion}

The three samples exhibited very similar behaviour in terms of variation of the contact area as a function of the applied normal force: the contact area increased sub-linearly with normal force, regardless of the temperature $\left(-2.5^{\circ} \mathrm{C}\right.$ (close to the melting temperature) and $-10^{\circ} \mathrm{C}$ ), as shown in figure 2 for rubber 1 . Very little or no adhesion could be detected during loading. However, during unloading, hysteresis appeared and a larger adhesion force was observed.

Due to the barrel-shaped rubber sample, an elliptical apparent contact was observed. Assuming no adhesion and according to Hertz' theory, the semi-major radii, $a$ and $b$, were calculated as follows [21]: 


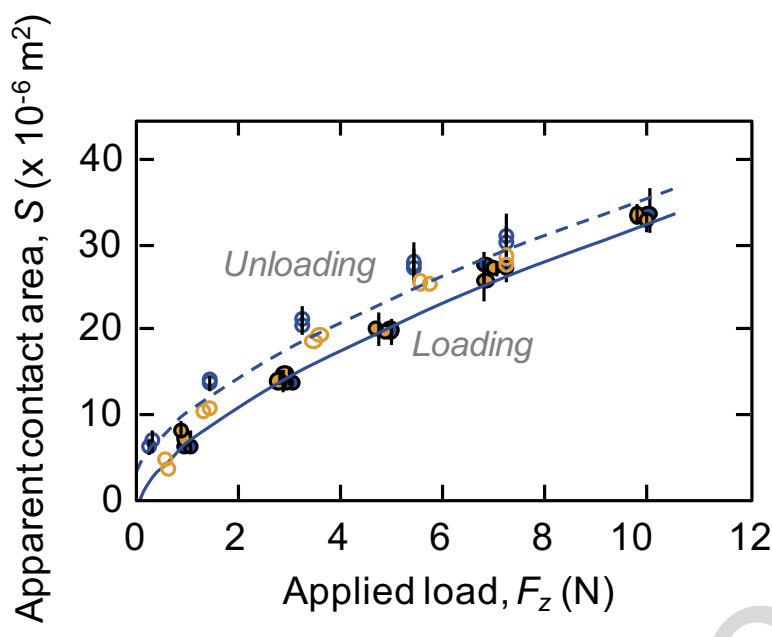

Figure 2: Variation of the apparent contact area as a function of the normal load for rubber 1 at $-10^{\circ} \mathrm{C}$ (blue symbols) and $-2.5^{\circ} \mathrm{C}$ (orange symbols). Loading and unloading steps are presented with full and empty symbols respectively. The vertical bars represent the standard deviation. When not indicated, it is smaller than the symbol size. The continuous and dashed lines correspond to Johnson-Kendall-Roberts adhesive contact models calculated with a shear modulus, $G^{*}$, of $1.2 M P a$ and an adhesive force, $F_{0}$, of $0.003 N$ during loading and $0.07 \mathrm{~N}$ during unloading.

$$
\begin{aligned}
& a=a_{1}\left(\frac{3 F_{z} R^{\prime}}{2 E^{*}}\right)^{1 / 3} \\
& b=b_{1}\left(\frac{3 F_{z} R^{\prime}}{2 E^{*}}\right)^{1 / 3}
\end{aligned}
$$

where $R^{\prime}$ is the reduced radius of curvature of the two solids (including the ice flat), $E^{*}$ the equivalent Young modulus using the elastic mechanical properties of ice, $E_{i c e}=9.5 \mathrm{GPa}$ and $\nu_{i c e}=0.33[20], a_{1}$ and $b_{1}$ depending on the ellipticity parameter, $k_{\text {ellipticity }}$, defined by:

$$
k_{\text {ellipticity }}=\frac{1 / R_{a}-1 / R_{b}}{1 / R_{a}+1 / R_{b}}
$$

This gave $k_{\text {ellipticity }}=0.35$, resulting in $a_{1}=1.25$ and $b_{1}=0.8$ [21]. The relative difference in contact area, between the elliptical case and the circular case, was less than $3 \%$. According to Johnson and Greenwood [22], this small difference was also confirmed by the ratio $R_{a} / R_{b}$ of about 2. Therefore, in first approximation, circular contact theories were used with a reduced radius of curvature $R^{\prime}=10.5 \mathrm{~mm}$. 
From the micrometer-scale investigation of rubber/ice interactions [12], as well as the literature [16], the work of adhesion was estimated at $30 \mathrm{~mJ} / \mathrm{m}^{2}$. This corresponds to an adhesive pull-off force, $F_{0}$, of $0.003 N$ accounting for the contact geometry. The plot of Johnson-Kendall-Roberts model for apparent contact area was presented in figure 2 with this value of $F_{0}$ and $G^{*}=1.2 \mathrm{MPa}$ for rubber 1 , with $G^{*}=E_{\text {rubber }} /\left(2+\nu_{\text {rubber }}\right)=E_{\text {rubber }} / 2.5$. This value of shear elastic modulus was consistent with DMA measurements at a frequency of $0.01 \mathrm{~Hz}$ for a large deformation strain (about $10 \%$ ). During JKR experiments, the deformation was static and of the same order of magnitude, $\epsilon \approx 4.3 \%$ with the radius of contact approximated by $3.9 \mathrm{~mm}$ and the equivalent radius of the two solids $R=\sqrt{R_{a} R_{b}} \approx$ $22.4 \mathrm{~mm}$. As can be seen in figure 2, this approach well predicted the evolution of the contact area vs the normal force during loading. Similar values, $G^{*}=1.15 M P a$ and $2 M P a$, were obtained for rubbers 2 and 3, respectively, in agreement with DMA measurements for large deformation strain. During unloading, larger values of pull-off force, $F_{0}$, were required to fit the experimental data, with $F_{0}=0.07 \mathrm{~N}$ for rubber $1,0.1 \mathrm{~N}$ for rubber 2 and $0.15 \mathrm{~N}$ for rubber 3. This increase in adhesive force was presumably attributed to the transfer of rubber and oil over the ice surface [12]. These enhanced values corresponded to work of adhesion values ranging from 700 to $1500 \mathrm{~mJ} / \mathrm{m}^{2}$-much higher than the surface energy of rubber, meaning that the ice-rubber contact was energetically favourable.

After sliding, a similar analysis was carried out, showing that the surface effect was significant. The work of adhesion was increased by a factor of 10 during loading and by 2 during unloading. This indicates a significant change in the surfaces properties (roughness and chemistry), most likely due to ice-rubber contact wear.

\subsection{In-situ evolution of the contact area during sliding}

Similar evolutions of the apparent contact area were observed for the three rubbers according to the sliding velocity and are illustrated in figure 3 for rubber 1 :

- The values of the contact area clearly depend on the rubber, stiffer rubber leading to a smaller contact area. The values were around $34 \pm 1 \mathrm{~mm}^{2}$ for rubbers 1 and $2\left(G^{*}=1\right.$ $\mathrm{MPa})$ and around $26 \pm 1 \mathrm{~mm}^{2}$ for the stiffer rubber $3\left(G^{*}=1.4 \mathrm{MPa}\right)$.

- The dynamic contact area was slightly lower than the static one, regardless of the 


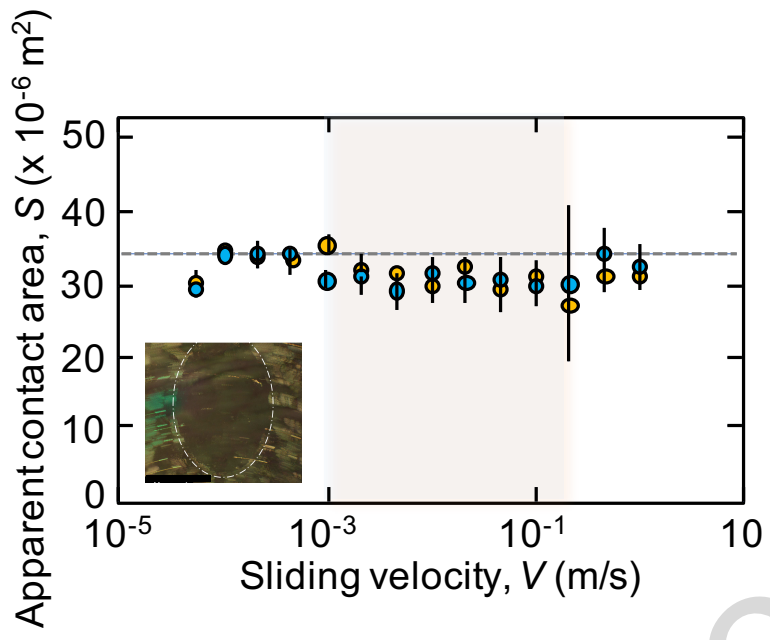

Figure 3: Evolution of the apparent contact area during sliding for rubber 1 at $-10^{\circ} \mathrm{C}$ (blue symbols) and $-2.5^{\circ} \mathrm{C}$ (orange symbols) under an applied normal force of $10 \mathrm{~N}$. The dashed grey line corresponds to the static contact. The vertical bars represent the standard deviation. When not indicated, it is smaller than the symbol size. The inset illustrates the in-situ contact visualization. The apparent contact area was obtained, in this example for a velocity of $0.21 \mathrm{~mm} / \mathrm{s}$ at $-10^{\circ} \mathrm{C}$ and $10 \mathrm{~N}$, the size of the image being $11.2 \times 9 \mathrm{~mm}^{2}$.

rubbers and of the temperature, especially for sliding velocities ranging from $1 \mathrm{~mm} / \mathrm{s}$ to $200 \mathrm{~mm} / \mathrm{s}$.

- The elliptical shape was maintained, regardless of the sliding velocity, at $-2.5^{\circ} \mathrm{C}$.

- By contrast, at $-10^{\circ} \mathrm{C}$, the shape became semi-elliptical between $1 \mathrm{~mm} / \mathrm{s}$ and 100 $\mathrm{mm} / \mathrm{s}$. This shape modification was presumably due to contact oscillations, observed on the recorded videos, such as stick-slip phenomena or detachment waves [23] caused by rubber adhesion on the ice. Another explanation could be an increase in shear stress, causing a decrease in contact area, as proposed by [24]. This observation for a limited range of sliding velocities might also indicate a change in the nature of the ice surface, such as the existence of a 'quasi-liquid'/ice premelting layer [25] and/or melting due to frictional heating within the contact.

No wear was detected during these sliding experiments. 


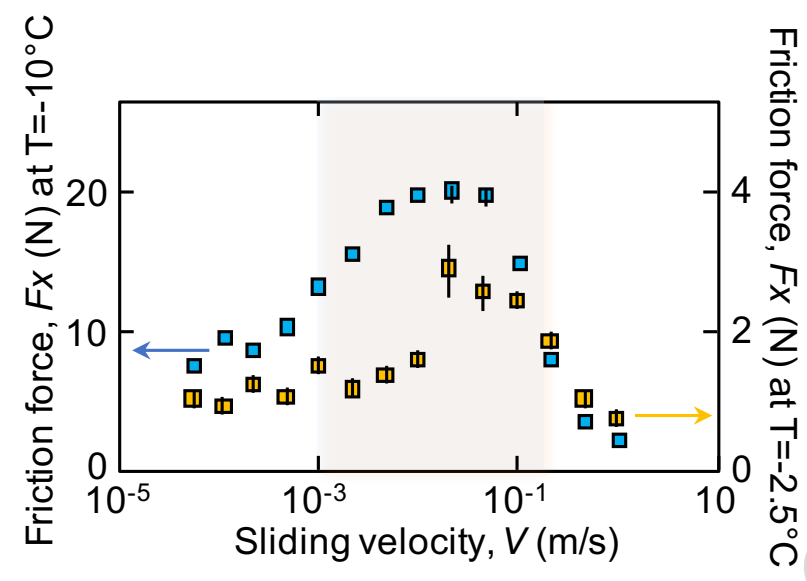

Figure 4: Bell-shaped friction force vs sliding velocity curves for rubber 1 at $-10^{\circ} \mathrm{C}$ (blue symbols) and $-2.5^{\circ} \mathrm{C}$ (orange symbols) under an applied normal force of $10 \mathrm{~N}$. The vertical bars represent the standard deviation. When not indicated, it is smaller than the symbol size.

\subsection{Friction behaviour and viscoelasticity}

For each velocity, after a short transient phase during which the friction force increased linearly with sliding time, it reached a stabilized plateau. The normal force remained constant. In order to investigate the friction mechanisms, the average friction force was calculated between 85 and $95 \%$ of the step duration, i.e. between 24 and $28 s$. An example of the friction force evolution as a function of the sliding velocity is illustrated in figure 4 for rubber 1 and two temperatures, $-10^{\circ} \mathrm{C}$ and $-2.5^{\circ} \mathrm{C}$.

Both plots (at $-10^{\circ} \mathrm{C}$ and $-2.5^{\circ} \mathrm{C}$ ) show a bell-shaped curve. When the values of friction increased, those of contact area decreased (see figure 3). The friction maximum occurred at about $20 \mathrm{~mm} / \mathrm{s}$, regardless of the temperature, at $20 \mathrm{~N}$ for $-10^{\circ} \mathrm{C}$ and $3 \mathrm{~N}$ for $-2.5^{\circ} \mathrm{C}$. It then strongly decreased and all friction values were superimposed above $0.1 \mathrm{~m} / \mathrm{s}$. This bellshape friction curve has been observed in the classical tribological-contact literature involving rubbers. This shape was attributed to the viscoelastic properties [4] [26] [13]. Friction values obtained by [4] [13] were of the same order of magnitude. This general trend was also observed with all three rubbers and at all the temperatures investigated.

Knowledge of the in-situ contact area allowed the calculation of the interfacial shear stress, which ranged between 0.1 and $1 \mathrm{MPa}$. The evolution of the shear stress as a function of the sliding velocity is presented in figure 5 for the three rubbers at $-10^{\circ} \mathrm{C}$ (a) and $-2.5^{\circ} \mathrm{C}$ 

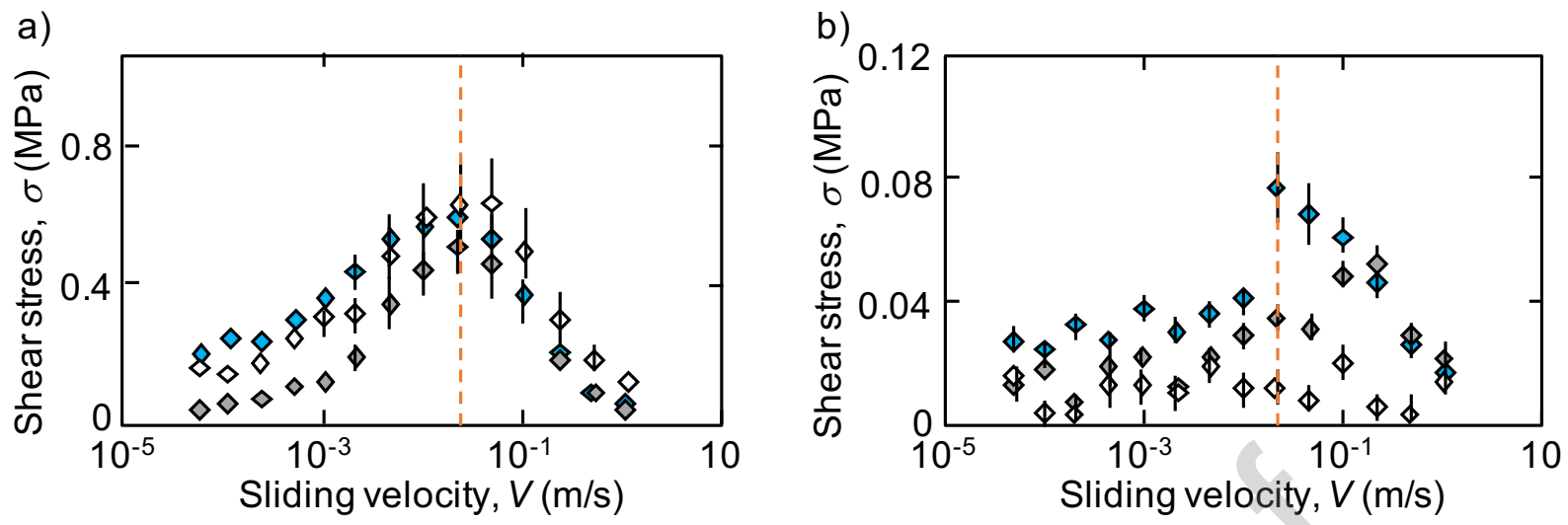

Figure 5: Shear stress calculated from friction data and in-situ contact area measurement vs sliding velocity at $-10^{\circ} \mathrm{C}$ (a) and $-2.5^{\circ} \mathrm{C}$ (b) under an applied normal force of $10 \mathrm{~N}$, for rubber 1 (blue symbols), rubber 2 (grey symbols) and rubber 3 (hollow symbols). The viscoelastic properties varied from $G^{*}=1$ and $1.4 \mathrm{MPa}$ and the glass temperatures were $T_{g}=-50$ or $-40^{\circ} \mathrm{C}$. The position of the maximum of shear stress for rubber 1 was also indicated with a vertical line. The vertical bars represent the standard deviation. When not indicated, it is smaller than the symbol size.

(b).

The shear stress was lower at $-2.5^{\circ} \mathrm{C}$ than at $-10^{\circ} \mathrm{C}$. This suggested a strong influence of temperature, regardless of the sliding velocity and of the rubber and its viscoelastic properties. This is in agreement with the observations of Jellinek [27] and the hypothesis of the existence/formation of a liquid-like layer on ice at temperatures close to the melting point.

Nevertheless, a maximum in shear stress was detected at both temperatures for all the rubbers. At $-2.5^{\circ} \mathrm{C}$, the position of this peak seemed to vary with the viscoelastic properties of the rubbers and a higher shear stress was measured for rubber 1 compared to rubbers 2 and 3. These results seem to indicate that at $-2.5^{\circ} \mathrm{C}$, the stiffer the rubber, the lower the shear stress. At $-10^{\circ} \mathrm{C}$, the lower the $T_{g}$ the higher the shear stress for low velocities although the stiffness influence might become dominant at high velocities. The position of the maximum shear stress was independent of the rubber.

Following the successful approach proposed in the literature [14] [13] based on the WilliamLandel-Ferry transformation, a tentative velocity shift of the rubber-ice friction curve was performed assuming:

- The validity of the time-temperature superposition. 
- The validity of the temperature-sliding velocity range in which the friction was measured compared to the one where the rubber was in its 'rubbery' state.

Taking the reference temperature at $0^{\circ} \mathrm{C}$, DMA data were superimposed using $C_{1}=$ 8.86 and $C_{2}=140 \mathrm{~K}$ for the three rubbers, consistently with the classical values found in the literature for elastomer, that is to say $C_{1}=8.86$ and $C_{2}=101.5 \mathrm{~K}$. This validated the assertion that viscoelastic properties obeyed WLF theory for the temperature range corresponding to the rubbery state above $T_{g}$. Using these parameters, the shift term $\alpha_{T}$ $=V_{\text {ref }} / V_{T}$ was calculated with $V_{\text {ref }}$ being the sliding velocity at temperature $T_{r e f}, V_{T}$ the sliding velocity at temperature $T$. It gave:

$$
V_{\text {ref }}=V_{T} 10^{-\frac{C_{1}\left(T-T_{\text {ref }}\right)}{C_{2}+T-T_{\text {ref }}}}
$$

The shift of the friction curves provided disappointing results: the friction curve at $2.5^{\circ} \mathrm{C}$ could not be superimposed on any other data; a partial superimposition being observed between 2 and $40 \mathrm{~mm} / \mathrm{s}$ at -7 and $-15^{\circ} \mathrm{C}$; the position of the friction peak differed for each set of data; the friction completely differed for high sliding velocities. These statements remained valid, regardless of the rubber.

To summarize, these in situ friction experiments suggested a coupling between the tem-

perature of the environment, the sliding velocity and the rubber viscoelasticity -far more complex than the classical view in which viscoelasticity governs friction at low velocities and thermal effects dominate at high velocities.

\subsection{Thermal analysis}

In order to further investigate the thermal contribution to friction, a simple thermal model was proposed. Going back to the pioneering work of Jaeger [28] and partitioning the friction-induced heat flux between the two semi-infinite solids [29] in a semi-elliptical contact [30], here the ice and the rubber, without loss, the model also assumed that:

- The transient thermal regime was negligible.

- The heat flux was considered to be established. 


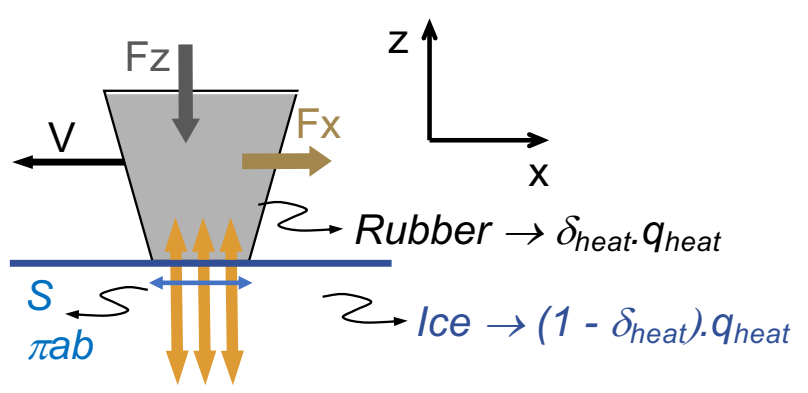

Figure 6: Schematic of a rubber sample sliding at velocity $V$ over an ice substrate under an applied normal load $F_{z}$. The friction-induced heat $q_{\text {heat }}$ was partitioned according to the ratio $\delta_{\text {heat }}$ in the rubber and $1-\delta_{\text {heat }}$ in the ice. The contact temperature became $T_{c}$.

- There was no thermal power generated in the ice or in the rubber, meaning that no phase transition took place.

- The temperature at the surface, either $T_{\text {rubber }}$ or $T_{i c e}$, was homogeneous over the entire ice-rubber interface.

- The heat source was considered immobile for the rubber and mobile for the ice.

A schematic of the considered interface is illustrated in figure 6 .

Within this framework, the temperatures $T_{\text {rubber }}$ and $T_{i c e}$ could then be calculated using:

$$
T_{\text {rubber }}-T_{0}=\frac{3 \pi}{8} \frac{\delta_{\text {heat }} q_{\text {heat }} b}{k_{\text {rubber }} \sqrt{S_{e}}}
$$

and

$$
T_{i c e}-T_{0}=2.32 \frac{\left(1-\delta_{\text {heat }}\right) q_{\text {heat }} b}{k_{\text {ice }} \sqrt{\pi\left(1.234 S_{e}+P_{e}\right)}}
$$

with $T_{0}$ the temperature far from the contact, here the environment temperature, $\delta_{\text {heat }}$ the partition coefficient expressing the ratio of heat flux entering the rubber and $1-\delta_{\text {heat }}$ representative of the corresponding heat flux entering the ice, $q_{\text {heat }}$ the average flux created within the sliding contact, $k_{i c e}$ and $k_{\text {rubber }}$ being the thermal conductivity of ice and rubber respectively, $S_{e}$ the function characteristic from elliptical heat sources and $P_{e}$ the Peclet number. 


$$
S_{e}=\frac{16(a / b)^{1.75}}{\left[3+(a / b)^{0.75}\right]\left[1+3(a / b)^{0.75}\right]}
$$

and,

$$
P_{e}=\frac{V b}{2 \alpha_{i c e}}
$$

with $\alpha_{i c e}$ the thermal diffusivity of ice.

In the contact, $T_{\text {rubber }}=T_{i c e}=T_{c}$ and the partition coefficient $\delta_{\text {heat }}$ was calculated from:

$$
\delta_{\text {heat }}=\frac{18.56 k_{\text {rubber }} \sqrt{S_{e}}}{18.56 k_{\text {rubber }} \sqrt{S_{e}}+3 \pi k_{\text {ice }} \sqrt{\pi\left(1.234 S_{e}+P_{e}\right)}}
$$

The heat only originated from friction dissipation and:

$$
q_{\text {heat }}=\frac{F_{x} V}{\pi a b}
$$

Therefore, combining equations 5, 9 and 10, the contact temperature $T_{c}$ could be deduced as follows:

$$
T_{c}-T_{0}=18.56 \frac{3 \pi}{4} \alpha_{i c e} \frac{F_{x} P_{e} /(\pi a b)}{18.56 k_{\text {rubber }} \sqrt{S_{e}}+3 \pi k_{i c e} \sqrt{\pi\left(1.234 S_{e}+P_{e}\right)}}
$$

\subsection{Ice-rubber friction mechanisms}

A striking result emerged from the calculation and the plot of the dimensionless temperature increase, $\left(T_{c}-T_{0}\right) /\left(T_{m}-T_{0}\right)$ with $T_{m}$ the melting temperature, here $0^{\circ} \mathrm{C}$. Figure 7 presents the evolution of this ratio as a function of the sliding velocity.

The geometrical contact parameters at $10 \mathrm{~N}$ load for each rubber are reported in table 3 . These values were used for the calculations as Figure 3 demonstrated that the contact area only slightly depended on the velocity. The thermal properties of the ice were: $k_{i c e}=2.21$ $W / \mathrm{m} / K$ [31], $\alpha_{\text {ice }}=1.1410^{-6} \mathrm{~m}^{2} / \mathrm{s}$ and for the rubber, $k_{\text {rubber }}=0.216 \mathrm{~W} / \mathrm{m} / \mathrm{K}[32]$.

For the three rubbers and the four environmental temperatures, that is to say at 12 different experimental conditions, all data collapsed to form a friction/sliding velocity master curve, regardless of the environmental temperature and regardless of the viscoelastic properties. In addition, the maximum in the master curve was obtained for a velocity of $100 \mathrm{~mm} / \mathrm{s}$ 
Table 3: Experimentally measured contact size, $a$ and $b$, at $-10^{\circ} \mathrm{C}$ and $V=0.1 \mathrm{~mm} / \mathrm{s}$.

\begin{tabular}{ccc} 
Sample & $\mathbf{a}(\mathbf{m m})$ & $\mathbf{b}(\mathbf{m m})$ \\
\hline Rubber 1 & 3.88 & 2.87 \\
Rubber 2 & 3.47 & 2.90 \\
Rubber 3 & 3.40 & 2.53 \\
\hline
\end{tabular}

a)

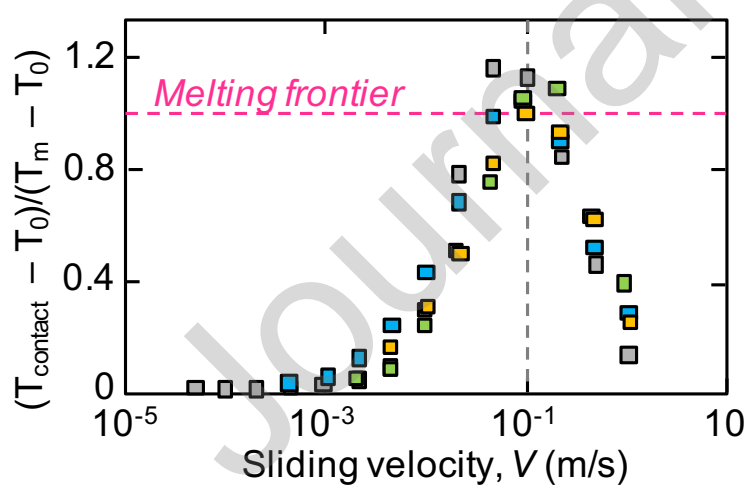

b)

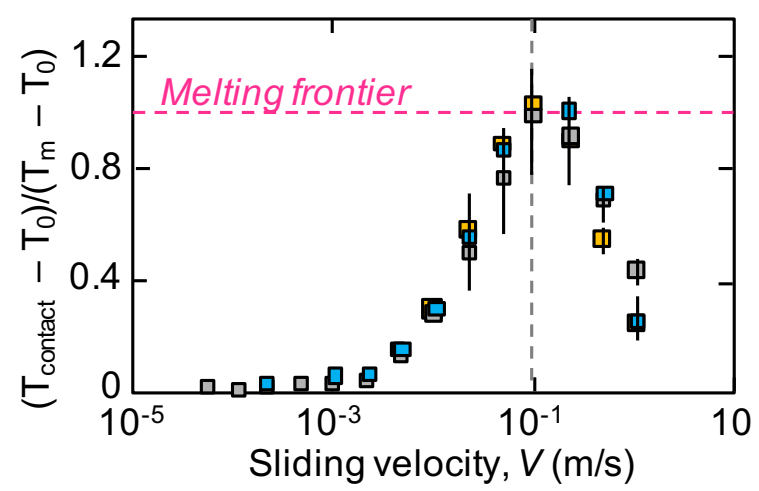

Figure 7: Dimensionless temperature increase ratio. (a) Influence of the temperature of environment for rubber 1 , with $-15^{\circ} \mathrm{C}$ (green), $-10^{\circ} \mathrm{C}$ (orange), $-7^{\circ} \mathrm{C}$ (blue) and $-2.5^{\circ} \mathrm{C}$ (grey squares).(b) Effect of the viscoelasticity at $-10^{\circ} \mathrm{C}$, with rubber 1 (orange), rubber 2 (grey) and rubber 3 (blue symbols). The vertical bars represent the standard deviation. When not indicated, it is smaller than the symbol size. 
in all cases, which differed from the maximum in shear stress (see Figure 5). This collapse of data indicated that the ice-rubber friction mechanisms were similar over the environmentaltemperature and material-property range investigated here. The existence of this master curve suggests that these mechanisms could be described using a dimensionless function, $\kappa(V)$, only dependent on the velocity and showing a maximum at $V=100 \mathrm{~mm} / \mathrm{s}$.

Then equation 11 can be rewritten to calculate the average interfacial shear stress, $\sigma$, as follows:

$$
\sigma=\rho_{i c e} c_{i c e}\left(T_{m}-T_{0}\right)\left(\frac{4}{3 \pi} \frac{\sqrt{S_{e}}}{P_{e}} \lambda_{k}+\frac{1}{4.64} \frac{\sqrt{\pi\left(1.234 S_{e}+P_{e}\right)}}{P_{e}}\right) . \kappa(V)
$$

with $\lambda_{k}=k_{\text {rubber }} / k_{i c e}, \rho_{i c e}$ the ice density and $c_{i c e}=\frac{k_{i c e}}{\rho_{i c e} \alpha_{i c i e}}$ the ice specific heat. In other words, the interfacial shear stress only depends on the thermal properties, the environmental temperature, the sliding velocity, with the viscoelasticity being taken into account via the contact size in $P e$, making the in-situ contact-area measurement highly relevant. According to equation 12 , the interfacial shear stress captures all the physics of the ice-rubber friction by decoupling the contribution of the thermal effects induced by frictional heating from that of the viscoelastic properties.

\subsection{Towards a friction model?}

Chernyak and Leonov's friction model for rubber vs another smooth solid surface was considered [8] as a first attempt to understand the physical meaning of $\kappa(V)$ and its bellshape evolution with velocity. In this model, the rubber friction is assumed to result from the dissipation due to the elongation, stretching and detachment of sections of macromolecules from the wall. This stochastic theory introduces times that are characteristic of the creation and breakage of adhesive linking chains from the surface, in order to calculate the evolution of the friction stress as a function of the sliding velocity. The friction stress was then normalized by a scale factor taking into account the elasticity of the rubber. Deriving this model for our configuration, we were able to predict the evolution of $\kappa(V)$ with the following characteristic times, in agreement with values obtained for rubbers [8]:

- The lifetime of an adhesive bond: $50 \mu s$. 
- The time to create a bond: $1 \mathrm{~ms}$.

- The critical sliding length: $1 \mu \mathrm{m}$.

- The molecular relaxation time: $30 \mu s$.

Figure 8 presents the predicted shear stress calculated using equation 12 with a constant contact area. These values were compared to the experimental values calculated with a constant contact area in a first approximation for mathematical convenience. This constant contact area equalled that measured at $0.1 \mathrm{~mm} / \mathrm{s}$, reported in table 3 . The experimental $\mathrm{in}$ situ shear stress, i.e. measured by accounting for the slight variation of the apparent contact area with the sliding velocity, was also indicated for reference. The predicted friction followed the experimental trend, meaning that the friction mechanisms were correctly captured in this first simple approach. It predicts more particularly that the position of the maximum shear stress differed from that of the occurrence of melting. The multiplicative coupling between thermal effects and adhesive viscoelasticity thus seems to govern ice-rubber friction behaviour.

The physical meaning of $\kappa(V)$, as assumed here using Chernyak and Leonov's model, would also explain the values of shear stress at high sliding velocities: despite rather low values, they remained too high to be considered as only to be resulting from the shear of a hydrodynamic water film. A residual adhesive viscoelastic contribution for this velocity range could contribute to these levels.

\section{Conclusions and outlook}

Ice-rubber friction mechanisms were investigated thanks to an experimental approach using the KŌRI tribometer, covering five decades of sliding velocities and at temperatures down to $-20^{\circ} \mathrm{C}$. The combination of in-situ contact visualization and simultaneous force measurements allowed us to analyse the adhesive behaviour and to get a direct measurement of the interfacial shear stress as a function of the rubber viscoelasticity, the sliding velocity and the environmental temperature.

- Direct evidence was presented that little adhesion occurred at the ice-rubber interface, regardless of the temperature. 


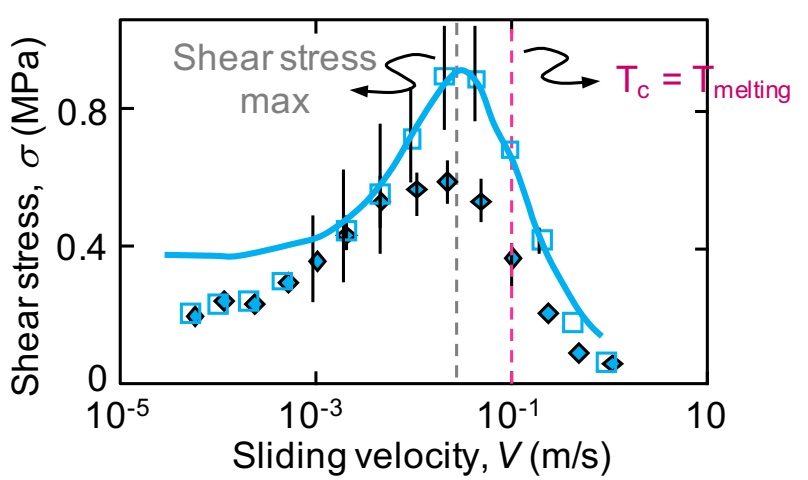

Figure 8: Evolution of shear stress with sliding velocity at $-10^{\circ} \mathrm{C}$ for rubber 1 . Experimental shear stress with $S=$ constant (blue empty squares) and blue line for predicted shear stress with $S=$ constant. The experimental in-situ shear stress is also reported for reference (blue full diamonds). The vertical bars represent the standard deviation. When not indicated, it is smaller than the symbol size.

- During sliding, the contact area was also independent of the temperature, being mainly governed by the mechanical properties of the rubber and only slightly dependent on the sliding velocity.

- Nevertheless, the interfacial shear-stress evolution with sliding velocity showed a bellshape curve with a maximum at intermediate velocity.

- The position of this maximum hardly varied with viscoelasticity.

From these results, a complex picture emerges, in which the rubber viscoelasticity does not dominate at low velocities, while the thermal effects do not govern the dissipation at higher velocity. The use of the WLF transform did not lead to a master curve. A simple analytical thermal model was proposed to calculate the friction-induced heat within the interface. We thus calculated the average contact temperature and analyzed the ice-rubber friction in terms of a dimensionless master curve, $\kappa(V)$, formed by the collapse of all the data, irrespective of the temperature and the material properties. The physical meaning of this master curve was then discussed and correlated with the adhesive-viscoelastic contribution. Finally, a predictive friction model was proposed and validated experimentally.

Our findings give new insights into how the interplay between adhesion-viscoelasticity and thermal dissipation affect the frictional response of an ice-rubber interface: friction was 
found to result from a multiplicative coupling between an adhesive-viscoelastic contribution, modelled here using Chernyak-Leonov description, and a thermal contribution.

\section{Acknowledgments}

This work was performed at the Laboratoire de Tribologie et Dynamique des Systèmes, Ecole Centrale de Lyon, CNRS UMR5513. It was funded by the CNRS with a BDI grant in the framework of ELyT Global, an international laboratory between CNRS, Tohoku University and University of Lyon (ELiceTrib project). The authors are grateful to Dr Yuji Kanno from Nihon Michelin, for providing the rubber samples and fruitful discussions.

\section{References}

[1] E.R. Pounder. The Physics of Ice. Pergamon Press, 1965.

[2] J.G. Dash, Haiying Fu, J.S. Wettlaufer. The Premelting of Ice and Its Environmental Consequences. Reports on Progress in Physics, 58:115-167, 1995.

[3] A.D. Roberts. A Guide to Estimating the Friction of Rubber. Rubber Chemistry and Technology, 65(3):673-686, 1992.

[4] K. Grosch. Visco-Elastic Properties and the Friction of Solids: Relation between the Friction and Visco-elastic Properties of Rubber. Nature, 197:858-859, 1963.

[5] A.D. Roberts. Theories of Dry Rubber Friction. Tribology International, 9(2):75-81, 1976.

[6] A.R. Savkoor, G.A.D. Briggs. On the Friction of Rubber. Wear, 8(3):222-237, 1965.

[7] A. Schallamach. A Theory of Dynamic Rubber Friction. Wear, 6:375-382, 1963.

[8] Y.B. Chernyak, A.I. Leonov. On the Theory of the Adhesive Friction of Elastomers. Wear, 108:105-138, 1986.

[9] A.I. Leonov. On the Dependence of Friction Force on Sliding Velocity in the Theory of Adhesive Friction of Elastomers. Wear, 141(1):137-145, 1990. 
[10] D. Tabor, J.C.F. Walker. Creep and Friction of Ice. Nature, 228:137-139, 1970.

[11] P. Oksanen, J. Keinonen. The Mechanism of Friction of Ice. Wear, 78:315-324, 1982.

[12] S. Hemette. Rubber-Ice Friction: A Multi-Scale and Multi-Physical Approach. PhD Thesis Ecole centrale de Lyon, 2019LYSEC17, 2019.

[13] E. Southern, R. Walker. Friction of Rubber on ice. Nature Physical Science, 237:142-144, 1972.

[14] W. Gnüeich, K.A. Grosch. The Friction of Polymers on Ice. Rubber Chemistry and Technology, 48(4):527-537, 1975.

[15] D.D. Higgins, B.A. Marmo, C.E. Jeffree, V. Koutsos, J.R. Blackford. Morphology of Ice Wear from Rubber-Ice Friction Tests and its Dependence on Temperature and Sliding Velocity. Wear, 265:634-644, 2008.

[16] A.D. Roberts, J.C. Richardson. Interface Study of Rubber-Ice Friction. Wear, 67:55-69, 1981.

[17] A.M. Kietzig, S.G. Hatzikiriakos, P. Englezos,. Physics of Ice Friction. Journal of Applied Physics, 107:081101, 2010.

[18] S. Hemette, J. Cayer-Barrioz, D. Mazuyer. Friction Setup and Real-Time Insights of the Contact under Controlled Cold Environment: The KŌRI tribometer for rubber-ice contact application. Review of Scientific Instruments, 89:123903, 2018.

[19] S. Hemette, M. Kasuya, F. Lecadre, Y. Kanno, D. Mazuyer, J. Cayer-Barrioz, K. Kurihara. Viscoelasticity of Rubber-Ice Interfaces Under Shear Studied Using LowTemperature Surface Forces Apparatus. Tribology Letters, 67:74, 2019.

[20] P.H. Gammon, H. Kiefte, M.J. Clouter, W.W. Denner,. Elastic Constants of Artificial and Natural Ice by Brillouin Spectroscopy. Journal of Glaciology, 29:433-460, 1983.

[21] A.W. Batchelor, G.W. Stachowiak. Engineering Tribology. Butterworth-Heinemann, 2001. 
[22] K.L. Johnson, J.A. Greenwood. An Approximate JKR Theory for Elliptical Contacts. Journal of Physics D: Applied Physics, 38:1042-1046, 2005.

[23] A. Schallamach. Friction and Frictional Rise of Wedge Sliders on Rubber. Wear, 13:13$25,1969$.

[24] A.R. Savkoor, G.A.D. Briggs. The Effect of Tangential Force on the Contact of Elastic Solids in Adhesion. Proc. R. Soc. Lond., A356:103-114, 1977.

[25] F. Lecadre, M. Kasuya, Y. Kanno, K. Kurihara. Ice Premelting Layer Studied by Resonance Shear Measurement (RSM). Langmuir, 35:15729-15733, 2019.

[26] K.A. Grosch, F.P. Bowden. Relation between the Friction and Visco-elastic Properties of Rubber. Proc. R. Soc. Lond., A274:21-39, 1963.

[27] H.H.G. Jellinek. Adhesive Properties of Ice. Journal of Colloid Science, 14(3):268-280, 1959.

[28] J.C. Jaeger. Moving Source of Heat and the Temperature at Sliding Contacts. Proc. R. Soc. NSW, 76:203-224, 1942.

[29] J.M. Georges. Frottement, Usure et Lubrification. Eyrolles CNRS Editions, 2000.

[30] F.E. Kennedy. Frictional Heating and Contact Temperatures. Modern Tribology Handbook, edited by B. Bhushan, CRC Press:235-272, 2000.

[31] A. Melinder. Properties and Other Aspects of Aqueous Solutions Used for Single Phase and Ice Slurry Applications. International Journal of Refrigeration, 33(8):1506-1512, 2010.

[32] J. Steen, W.J. Aben, K.E.D. Wapenaar. Optimization of the Vulcanization Process of Rubber Products. Polymer Engineering and Science, 33(3):183-189, 1993. 


\section{Graphical abstract}

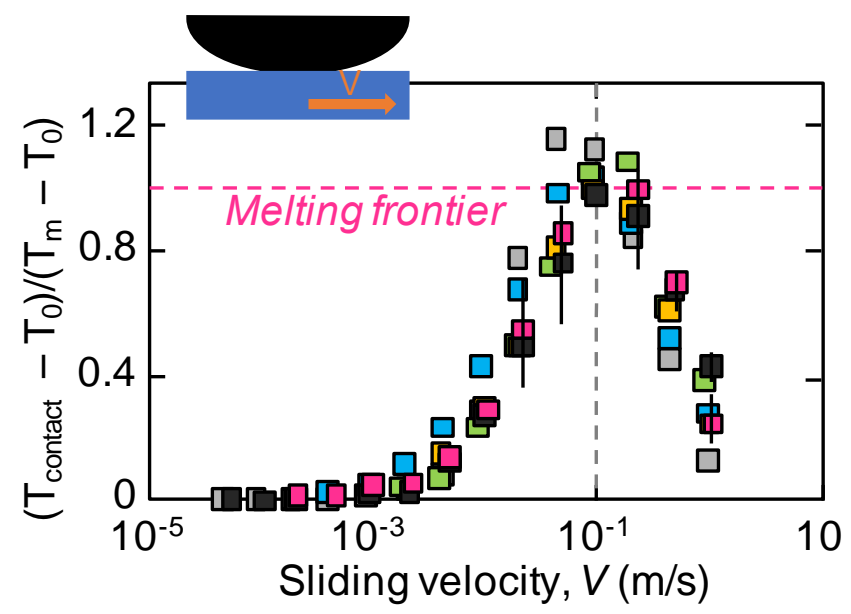

Friction mastercurve, for $\mathrm{G}$ varying from 1 to $1.7 \mathrm{MPa}, \mathrm{T}_{\mathrm{g}}$ ranging from $-40^{\circ} \mathrm{C}$ and $-50^{\circ} \mathrm{C}$ and environmental temperature between $-15^{\circ} \mathrm{C}$ and $0^{\circ} \mathrm{C}$ 
Authors' contributions: JCB and DM designed the study and wrote the initial version of the manuscript. Data collection was performed by SH. Analysis was performed by SH, DM and JCB. Manuscript editing and revisions were performed by DM and JCB. 
The authors declare that they have no known competing financial interests or personal relationships that could have appeared to influence the work reported in this paper. 


\section{Highlights}

- Ice-rubber friction over five decades of sliding speeds and temperature down to $20^{\circ} \mathrm{C}$

- Investigation of the adhesive and viscoelastic contributions

- Analytical modelling of the thermal dissipation

- Friction mastercurve, regardless of viscoelasticity and environmental temperature

- Multiplicative viscoelastic-thermal contributions to friction mechanisms 